\title{
Object attachment and the critical period
}

Well past normally accepted critical periods, social isolation and darkness appear to contribute to the process that leads to a bird-object attachment.

In view of the theoretical significance of the discovery of a critical period for imprinting in precocial birds, it is surprising that some authors in the recent literature (Hess, 1964; Moltz, 1963) have ignored the fact that precocial birds will follow an inanimate object well beyond this period (12 to $72 \mathrm{hr}$. depending upon experimental conditions) in the absence of any opportunity for the object to have acquired secondary reinforcing properties. Guiton (1958) observed 12 brown leghorn chicks raised communally until they were 3-1/2 days old and then tested for following with a stuffed cockerel. None of these chicks followed the silent model. He then retained six $S s$ in a communal brooder and socially isolated the remaining six Ss. He imposed these two conditions for $5-1 / 2$ days and then again tested all of the Ss. None of the six communallyraised Ss followed the model, whereas four of the six isolated Ss did follow.

The present study was carried out in ignorance of Guiton's work. Its design permits one to check Guiton's findings and, in addition, to determine the effect of an extended period of darkness upon the object-attachment of precocial birds.

\section{Method and Procedure}

Eleven hatched Peking ducklings were kept communally in a cardboard box from birth and were approximately 16-18 hr. old when they were separated. They were separated in the following way with each group in a separate room.

Group isolated dark (GID): Four Ss were placed in individual cages and kept in the same room visually and tactually isolated from one another.

Group isolated light (GIL): Three Ss were isolated in the same way as the Ss under condition (GID).

Group dark (GD): Two Ss were kept together in a single cage.

Isolated light (IL): One $S$ was kept alone in a room to himself.

Isolated dark (ID): One $S$ was kept alone in a room to himself.

For the first 11 days after the birth of these Ss, the lights in all of the rooms were kept on an artificial day-night cycle so that they were on approximately $10 \mathrm{hr}$. and off approximately $14 \mathrm{hr}$. On days 10 and 11 , all of the ss were tested for following. They were placed in a circular alley which was $10.5 \mathrm{in}$. wide, $11.0 \mathrm{in}$. high, and $32.0 \mathrm{in}$. in outside diameter. The moving object was a green rectangular box 6.0 in. high, and $4.0 \mathrm{in}$. square in cross section. The object made one revolution every $15 \mathrm{sec}$. The object was kept moving for $10 \mathrm{~min}$., was stopped for $5 \mathrm{~min}$, to give the following animals a rest, and finally was kept moving again for $10 \mathrm{~min}$. Thus, each $\mathrm{S}$ was tested for $20 \mathrm{~min}$. on days 10 and 11 . When all Ss had been tested, the lights were turned off for seven days for the GID, GD, and ID animals. The artificial day-night schedule was maintained for the GIL and IL animals. On days 18 and 19, all Ss were tested again for following. On day 19, the artificial day-night schedule was resumed for all animals and on day 25, all of the Ss were again tested for following. On day 26, two of the Ss were placed in the alley in a Plexiglas enclosure. The object was placed approximately $14 \mathrm{in}$. away from the enclosure, and each of the remaining nine Ss was placed midway between the enclosure containing the display ducklings and the object. Each $S$ was allowed to move toward either the ducklings or the object. Two $\mathrm{min}$. were allowed for this choice behavior. The object was then started moving very slowly away from the display Ss and the experimental Ss were scored on their choice to either stay near the display Ss or follow the object.

\section{Results and Discussion}

Since we have observed that precocial birds frequently fail to follow when exposed to a silent moving object during the first day of life but do follow readily the next day on their second exposure, it was decided to look at the Ss' following scores beginning with the second day (day 11) of testing. Only complete revolutions were counted toward an S's following score. Table 1 shows the following scores (and measures of attachment other than following) for all Ss and the choices that nine of the Ss made when faced with both the object and the display Ss.

The data for day 11 confirms Guiton's findings in that five of the $11 \mathrm{Ss}$ exhibited following behavior. It is interesting to note that $\mathrm{S}$ No. 10 in the GD group did a considerable amount of following in spite of the fact that he was housed together with $\mathrm{S}$ No. 11 during those days when the artificial day-night cycle was imposed. Thus, contrary to Guiton's findings, it would appear that following can occur in communally-raised birds if one is willing to accept in his definition of communal situations a single cage with only two Ss in it.

Although five of the 11 Ss followed the object on day 11. Table 1 shows that on day 18 nine Ss followed, preceded, blocked (2), or exhibited some combination of these behaviors. The preceding and blocking seemed to involve an attachment to the object in view of the fact that ss peeped contentedly while exhibiting these 
Table 1. The total number of complete revolutions out of 80 possible are shown for days $11,18,19$, and 25 . The choices that $S$ s made between the object and the display Ss on day 26 are shown.

\begin{tabular}{|c|c|c|c|c|c|c|}
\hline S\# & Day 11 & $\begin{array}{l}\text { Experimental } \\
\text { condition during } \\
\text { days } 11-18\end{array}$ & Day 18 & Day $19^{a}$ & Day 25 & $\begin{array}{l}\text { Choice } \\
5 \text { day } 26\end{array}$ \\
\hline $\begin{array}{l}1 \\
2\end{array}$ & $\begin{array}{r}30 \\
0\end{array}$ & $\frac{\mathrm{IL}}{\mathrm{ID}}$ & $\begin{array}{l}10 \\
0^{b}\end{array}$ & $\begin{array}{l}3 \\
0 b\end{array}$ & $\begin{array}{l}59 \\
0 b c\end{array}$ & $\begin{array}{l}\text { ducks } \\
\text { object }\end{array}$ \\
\hline 3. & 10 & GIL & 10 & 0 & 0 & ducks \\
\hline 4 & 0 & GIL & 0 & 0 & 0 & display duek \\
\hline 5 & 0 & GIL & 0 & 0 & $0^{c}$ & object \\
\hline 6 & 40 & GID & $10^{c}$ & $3^{c}$ & 55 & object \\
\hline 7 & 7 & $G \mid D$ & $12^{b c}$ & $27^{c}$ & $0^{c}$ & object \\
\hline 8 & 0 & GID & $9 b c$ & $35^{c}$ & $17^{c}$ & object \\
\hline 9 & 0 & GID & 54 & 30 & 68 & ducks \\
\hline 10 & 44 & GD & 57 & $3^{c}$ & $6 c$ & ducks \\
\hline 11 & 0 & GD & 4 & 13 & 0 & display duek \\
\hline
\end{tabular}

a-Day-night cycle resumed for all animals during days 19-26.

$b$-Animal preceded object closely while emitting contented peeps and gave distress calls when object was out of sight.

c-Animal blocked object preventing it from moving and gave distress calls when object was out of sight.

behaviors and emitted distress calls when the object moved out of sight.

The animals that formed an attachment to the object on days 18 and 19 that had not done any following on day 11 were all from groups that were kept in the dark during days 11-18. Table 1 shows that through day 19 , only Ss Nos. 4 and 5 of group GIL had failed to show any attachment for the object. Unexplicably, S No. 3, also of the GIL group, stopped following for the rest of the experiment beginning with day 19. Equally inexplicably, on day $25, S$ No. 11 of the GD group quit following, but $S$ No. 5 of group GIL that had never displayed an attachment for the object began blocking. The blocking of $\mathrm{S}$ No. 5 was distinguished by being accompanied with distress calls as well as contented peeping.

Beyond Guiton's findings, the present experiment shows that an extended isolation-darkness period can establish a bird-object attachment in Ss which are well past the critical period and which did not display a previous attachment after they were kept in isolation on an artificial day-night cycle. Apparently, both extended darkness and extended isolation influence object attachment. The relative contribution of these factors should become accessible via parametric studies.

The choice tests confirmed Hess' (1964) finding that attachment to a moving object can be independent of the choice that an animal makes between that object and something else. Table 1 shows that some of the Ss with the highest following scores failed to choose the object during the choice tests. S No. 3 would have been expected to choose the ducks since it failed to show any form of attachment for the moving object on days 19 and 25, but Ss Nos. 1, 9, and 10, which also chose the ducks, had displayed an attachment for the moving object during all of the test sessions on days 18, 19, and 25. Ss Nos. 2 and 5 chose the object although they never followed it when it was moving (they did, however, display preceding and/or blocking). Ss Nos. 6, 7, and 8 showed strong signs of attachment (including following) and they also chose the object.

The relationship between object attachment and object choice would thus seem to be difficult to predict. Hess (1964) has shown that animals may follow and yet "fail" the choice test if they are given social experience prior to exposure to a moving model (even though his Ss' first exposure to a moving model has always occurred within $72 \mathrm{hr}$. of birth). Hess has predicted that Ss will not choose a model if (1) they are given social experience prior to imprinting, and (2) the imprinting takes place outside of the critical period. The results of the present experiment do not support Hess' prediction in that five out of the nine Ss that were tested "passed" the choice test in spite of the fact that they had had social experience prior to imprinting and were imprinted well past the normally accepted critical period.

The question as to whether or not the birds in the present study were "truly" imprinted cannot be answered until there is strong agreement as to the conditions under which the term imprinting is to be used. If following is evidence of imprinting, then Ss Nos. $1,3,6,7,8,9,10$, and 11 were imprinted to a lesser or greater degree. If object choice is the criterion to be used, then Ss Nos. 2, 5, 6, 7, and 8 were imprinted, and if both following and object choice are to be the criteria, then Ss Nos. 6, 7, and 8 (add Ss Nos. 2 and 5 if preceding and/or blocking are included) were imprinted.

The results of the present study indicate that the conditions under which imprinting occurs in a natural setting may constitute only one among a number of sets of conditions that can elicit an attachment between a precocial bird and some object. Extended social isolation or extended periods of darkness may well be two potent variables capable of forcing such attachments.

\section{References}

Guiton, P. The effect of isolation on the following response of Brown Leghorn Chicks. Proc. Roy. phys. Soc. Edinburgh, 1958, 27, 9-14.

Hess, E. H. Imprinting in birds. Science, 1964, 146, 1128-1139. Moltz, H. Imprinting: an epigenetic approach. Psychol. Rev., 1963, $70,123-138$.

\section{Notes}

1. The author wishes to thank Dr. Laurence Stettner for his help in the preparation of this paper.

2. Some of the Ss "caught" the object and prevented it from moving. Subjects could (and some did) avoid the object by sitting close to the outer wall of the alley. 